\title{
¿Dónde está la garrapata? Crucero \& casa (resuelto en Atención Primaria)
}

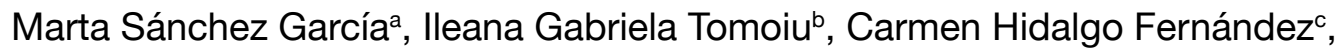 \\ José Andrés Delgado Casadoc
}

${ }^{a}$ Médico residente de $2^{\circ}$ año de Medicina Familiar y Comunitaria. Centro de Salud Ciudad Real II. Ciudad Real (España).

${ }^{\mathrm{b}}$ Médico residente de $4^{\circ}$ año de Medicina Familiar y Comunitaria. Centro de Salud Ciudad Real II. Ciudad Real (España).

c Especialista en Medicina Familiar y Comunitaria. Centro de Salud Ciudad Real II. Ciudad Real (España).

Correspondencia: Marta Sánchez García. Centro de Salud Ciudad Real II. C/ Palma, 11. 13001. Ciudad Real Correo electrónico: fenetra_444@ hotmail.com

Recibido el 27 de mayo de 2013.

Aceptado para su publicación el 28 de junio de 2013.

\begin{abstract}
RESUMEN
Trabajar en Atención Primaria supone pensar en las patologías más frecuentes que se dan en nuestro entorno. Un paciente joven que presenta úlceras genitales nos hace pensar en una infección de transmisión sexual. Sin embargo, la falta de respuesta al tratamiento empírico correcto y los resultados de la serología muestran el diagnóstico definitivo: fiebre botonosa mediterránea, con una localización poco común. Debemos recordar que una enfermedad común en nuestro medio puede parecerse a otra igualmente común, por lo que una correcta historia clínica será fundamental para distinguirlas.
\end{abstract}

Palabras clave: Úlcera. Fiebre Botonosa, Rickettsia conorii.

\section{ABSTRACT}

Where is the tick? Cruise \& home (resolved in primary health care)

Working in primary health care means thinking about the most common pathologies which we encounter in our workplace. A young patient with genital ulcers makes us think of a sexually transmitted infection. However, the lack of response to the correct empirical treatment and serology results show a definitive diagnosis: Mediterranean spotted fever (also known as boutonneuse fever), with a rare location. It should be remembered that a commonly occurring disease in our environment may resemble another equally common one, thus a correct clinical history is fundamental in order to distinguish them.

Key words: Ulcer. Mediterranean spotted fever. Rickettsia conorii.

\section{INTRODUCCIÓN}

La fiebre botonosa mediterránea es una enfermedad producida por Rickettsia conorii y transmitida por la garrapata del perro (Rhipicephalus sanguineus), aunque fuera del área mediterránea pueden actuar como vectores otros artrópodos. Suele aparecer durante el verano, cuando los vectores se muestran más activos. Se han detectado casos en todos los países del área mediterránea y también se han descrito algunos casos en el norte y centro de Europa. La incidencia de esta enfermedad ha ido aumentando en los últimos años, especialmente en el ámbito urbano.

\section{OBSERVACIONES CLÍNICAS}

Varón de 18 años que ha realizado un crucero por Túnez, Malta y Grecia como viaje de estudios. A los 10 días de su regreso, comienza con odinofagia y fiebre de $39-40^{\circ} \mathrm{C}$.

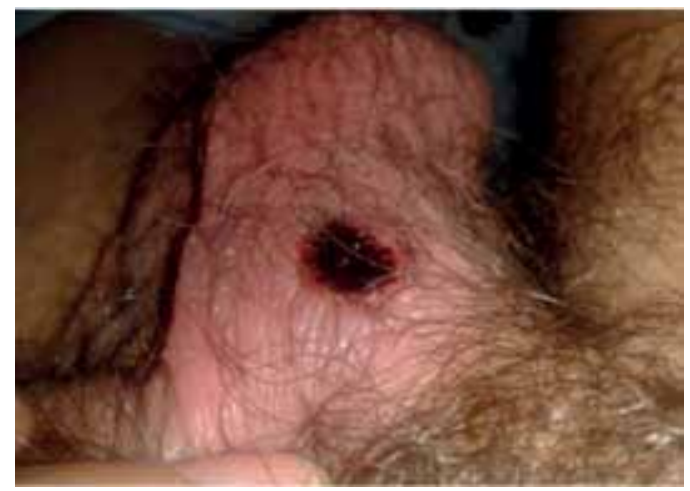

Figura 1. El paciente presenta, en el testículo, una lesión ulcerosa de fondo negruzco con bordes eritematosos. 


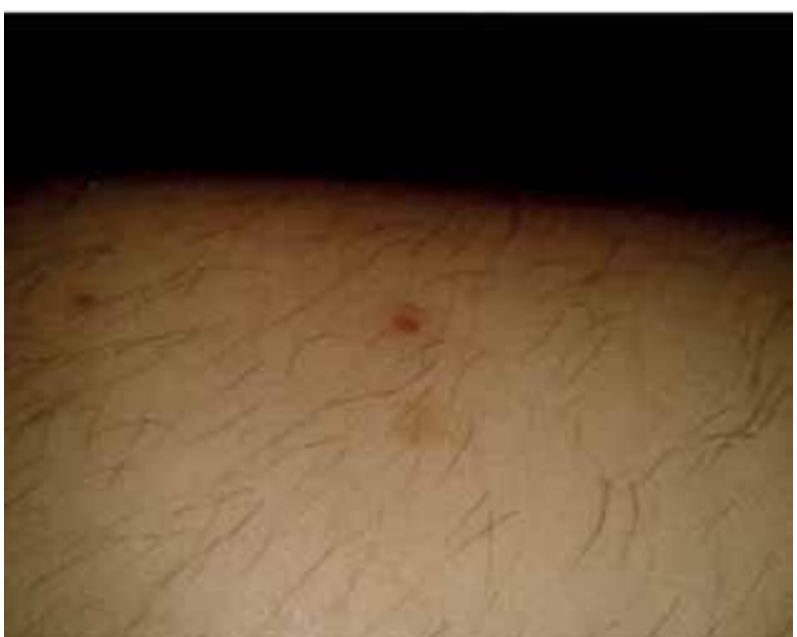

Figura 2. Erupción en miembros inferiores, máculo-papulosa, en número de 7-8, que comienza dos días después de la aparición de las lesiones en los testículos.

Tras debutar con esta clínica, al día siguiente aparecen 2 lesiones en los testículos (figura 1), y dos días después, aparece una erupción máculopapulosa en los miembros inferiores (MMII) (figura 2). El paciente inicia, sin consultar con su médico de familia, tratamiento con amoxicilina.

Acude a nuestra consulta a los 7 días del comienzo del cuadro, al no experimentar mejoría tras el tratamiento con amoxicilina, persistiendo la fiebre y las lesiones cutáneas. Al realizar la anamnesis, el paciente comenta que presenta estomatitis aftosa recidivante, sin otros antecedentes personales de interés. Niega contactos ni conductas de riesgo durante su viaje. Durante la consulta, nos comenta que tiene varios animales en casa, entre ellos, dos perros, un ave y dos cobayas.

En la exploración física objetivamos fiebre y varias aftas bucales, como suele ser habitual en el paciente. No presenta adenopatías laterocervicales, supraclaviculares ni inguinales. Presenta dos lesiones ulcerosas en los testículos, de $0,5 \mathrm{~cm}$ aproximadamente, negras, de bordes eritematosos. En los MMII se objetivan lesiones máculo-papulosas, en número de 7-8. El resto de la exploración es normal.

Una vez realizada la anamnesis y ante la exploración física referida, pensamos en la posibilidad de que se trate de una infección de transmisión sexual (ETS) que produzca úlcera genital: sífilis, linfogranuloma venéreo, chancroide (chancro blando) o granuloma inguinal. Como el paciente niega conductas de riesgo, nos planteamos otros posibles diagnósticos: infección por citomegalovirus (CMV),

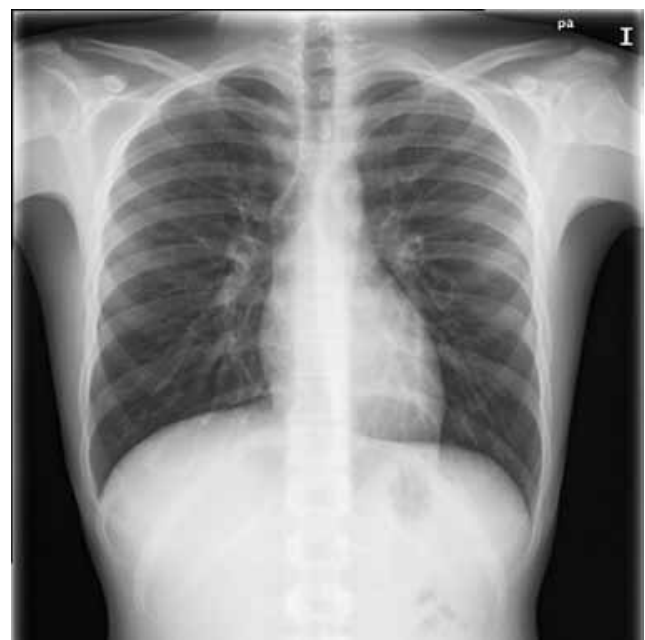

Figura 3. Radiografía de tórax del paciente, en la que no se objetivan hallazgos patológicos y es compatible con la normalidad.

infección por virus de Epstein-Barr (VEB), fiebre botonosa mediterránea e infecciones por parásitos (helmintiasis).

Solicitamos una radiografía de tórax (figura 3), en la que no se objetivan hallazgos patológicos, y una analítica completa que incluye serología frente a CMV, VEB, sífilis, rickettsias y clamidias. A la espera de los resultados, y dada la falta de respuesta al tratamiento con amoxicilina, se inicia tratamiento empírico con aciclovir $800 \mathrm{mg} / 8$ horas y doxiciclina $100 \mathrm{mg} / 12$ horas, con el fin de tratar las posibilidades diagnósticas principales: herpes genital y otras infecciones. Con este tratamiento, la fiebre desaparece en 48 horas y en los siguientes 5-7 días mejoran las lesiones cutáneas.

Una vez recibida la analítica, destaca una leucocitosis con desviación izquierda y un resultado serológico positivo para Rickettsia conorii, que nos confirma el diagnóstico: fiebre botonosa mediterránea.

\section{COMENTARIOS}

Las rickettsias son bacterias gramnegativas de pequeño tamaño, pleomórficas, que se comportan como parásitos intracelulares obligados y no pueden sobrevivir fuera del vector o del reservorio durante períodos prolongados. Pueden utilizar como vectores diferentes garrapatas, pero también pulgas y piojos.

Las garrapatas infectadas son capaces de transmitir la infección mientras se están alimentando a 
través de la misma picadura, de la hemolinfa por aplastamiento del vector o por contaminación de alguna solución de continuidad en la piel con las heces infectadas del artrópodo'.

Producen cuadros clínicos de gravedad variable, pero suelen inducir la tríada de fiebre, cefalea y erupción cutánea ${ }^{1-3}$.

En los últimos años se ha ampliado enormemente del número de especies dentro del género. Se clasifican en dos grupos, clásicamente: el de las fiebres manchadas y el de las fiebres tíficas. La fiebre botonosa mediterránea, causada por $R$. conorii, se incluye dentro del grupo de las fiebres manchadas. Se transmite por garrapatas infectadas. Fiebre, exantema, mancha negra (que no aparece en todos los casos, como en el que presentamos) e incidencia estacional en verano pueden establecerse como criterios de inclusión en el diagnóstico de la enfermedad. Las manifestaciones clínicas aparecen aproximadamente 10 días después de la picadura de la garrapata (5-20 días). En el $75 \%$ de los casos se produce una lesión ulcerada de bordes ligeramente elevados con un fondo negruzco que se rodea de un área eritematosa (mancha negra o tache noire) y suele ser única. El desarrollo del cuadro clínico suele ser brusco, con fiebre elevada, cefalea holocraneal, artromialgias de predominio en las piernas y un deterioro marcado del estado general. A partir del segundo día aparece característicamente una erupción eritematosa papulosa o maculopapulosa que se extiende rápidamente sin respetar las palmas de las manos o las plantas de los pies. En un tercio de los pacientes se detectan síntomas digestivos y hepatomegalia ${ }^{1-3}$. El pronóstico suele ser benigno. El tratamiento de elección es doxiciclina (100 $\mathrm{mg} / 12 \mathrm{~h}$ ) en pautas cortas (un solo día) y, como alternativas, pueden emplearse fluorquinolonas durante $7-10$ días 0 azitromicina $(500 \mathrm{mg} / 24 \mathrm{~h}$, durante 3-5 días) 1 .

Encontramos otras rickettsiosis del grupo de las fiebres manchadas, como la fiebre manchada de las Montañas Rocosas, causada por $R$. rickettsii, que cursa con síntomas inespecíficos (fiebre, postración, artromialgias) y erupción maculosa en tobillos y muñecas que se extienden a las palmas y plantas. Otros cuadros como la fiebre de Astrakhan (R. conorii caspia) o la viruela ricketsiósica ( $R$. akari) no se han detectado en nuestro entorno'.

Dentro del grupo de las fiebres tíficas, la infección más frecuente es el tifus murino, causado por $R$. typhi y transmitido a través de la picadura de la pulga de la rata Xenopsylla cheopis. El periodo de incubación es de 1-2 semanas. El cuadro clínico es brusco, y consiste en fiebre elevada, escalofríos, cefalea intensa, mialgias y náuseas. Pueden aparecer confusión, estupor, convulsiones y otros síntomas neurológicos. A los 3-5 días del inicio del cuadro puede aparecer una erupción eritematosa macular o maculopapular, que suele respetar las palmas y las plantas. El pronóstico es benigno y se resuelve con tratamiento antibiótico, siendo de elección la doxiciclina (100 mg/12 h) durante 7-10 días. Otros cuadros como el tifus epidémico ( $R$. prowazekii) y la fiebre de las malezas (Orientia tsutsugamushi) son similares.

En general, el pronóstico de las rickettsiosis es benigno, aunque algunas de ellas pueden llegar a ser mortales. La clínica aparece de forma brusca, y suele caracterizarse por erupciones cutáneas y afectación del estado general. El tratamiento de elección, como se ha visto, es la doxiciclina, pudiendo utilizarse como alternativas fluorquinolonas, cloramfenicol o azitromicina.

\section{BIBLIOGRAFÍA}

1. Herrero JA, García-Vázquez E, Hernández A, Gómez J. Infecciones por rickettsias y fiebre Q. Medicine. 2010; 10 (57): 3881-8.

2. Castro Jiménez RA, García Gallego JJ, Redondo Pedraza R, Quero Espinosa B. Fiebre botonosa mediterránea: a propósito de dos casos en área de asistencia primaria urbana. Semergen. 2006; 32 (1): 36-40.

3. Heras Salvat MG, Hernández Sastre I, Sagredo Pérez J. Fiebre botonosa mediterránea como caso urbano y familiar. FMC. 2004; 11 (7): 394-6. 